\title{
LEITURA DE TEXTOS VERBO-VISUAIS: A CONSTRUÇÃO DOS MODOS DESCRITIVO E NARRATIVO NOS QUADRINHOS
}

\author{
Glayci Kelli Reis da Silva Xavier
}

\begin{abstract}
RESUMO
O presente trabalho pretende estudar a leitura dos quadrinhos, verificando como se dá a construção dos modos narrativo e descritivo por meio da relação verbo-visual. A base teórica utilizada foi a Teoria Semiolinguística de Análise do Discurso de Patrick Charaudeau (1992; 2009a). Como corpus de análise, foram utilizadas tirinhas da Turma do Xaxado, de Antônio Cedraz.
\end{abstract}

PALAVRAS-CHAVE: quadrinhos; verbo-visualidade; semiolinguística.

\section{Considerações iniciais}

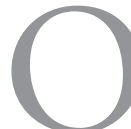

uando a tecnologia digital ainda não fazia parte tão ativamente da vida do ser humano, várias gerações cresceram lendo gibis. No entanto, tal tipo de leitura era marginalizado pela escola. Com o advento dos Parâmetros Curriculares Nacionais - PCNs - (MEC, 1997), valoriza-se um ensino de língua que privilegia o trabalho com a mais variada gama de gêneros discursivos. Nesse cenário, as histórias em quadrinhos ganharam espaço dentro da escola e continuam presentes na vida dos alunos.

Por isso, torna-se necessário aprofundar o conhecimento a respeito desse gênero e de suas variaçóes, de forma a proporcionar instrumentos que possam levar os educandos a conhecer e a aplicar estratégias de leitura de textos verbo-visuais seu dia a dia. Como afirma Kress (2000, p. 337), é impossível agora 
compreender os textos, até mesmo em as suas partes linguísticas somente, sem ter uma clara ideia de como os outros elementos (visuais) podem contribuir para seu significado.

A história em quadrinhos é um gênero que lida com dois dispositivos importantes de comunicação: palavras e imagens (EISNER, 1989, p. 7); palavras são feitas de letras e letras são imagens. Desse modo, nos quadrinhos, o leitor tem uma dupla atividade, pois cada elemento visual tem um significado. Conforme explica Eisner (2005, p. 9), o processo de leitura dos quadrinhos é uma "extensão do texto"; num texto verbal, o leitor precisa converter a palavra em imagens, enquanto, nos quadrinhos, esse processo é acelerado, pois as imagens são fornecidas. Dessa forma, em um texto verbo-visual como as histórias em quadrinhos, as imagens exercem, assim como as palavras, as funçóes descritiva e narrativa.

Nessa perspectiva, o presente trabalho pretende verificar como se dá a construção dos modos descritivo e narrativo e os efeitos produzidos por meio da relação verbo-visual nos quadrinhos. Como corpus de análise, serão utilizadas tirinhas da Turma do Xaxado, de Antônio Cedraz. A fundamentação teórica em que se baseou essa pesquisa foi a Teoria Semiolinguística de Análise do Discurso de Patrick Charaudeau (1992; 2009a), com relação aos sujeitos do ato de linguagem e os modos de organização do discurso.

\section{Histórias em quadrinhos e verbo-visualidade}

As histórias em quadrinhos, também conhecidas como $\mathrm{HQ}$, bandas desenhadas, comix ou simplesmente gibis, são "um dos mais difundidos e populares meios de fabulação visual do planeta" (PATATI \& BRAGA, 2006, p. 9). Dependendo do suporte e do estilo, é possível situar as histórias em quadrinhos numa "constelação de gêneros não verbais ou icônico-verbais assemelhados" (MENDONÇA, 2002, p. 197).

De acordo com O’Neill (2005, p. 10), os quadrinhos não são simplesmente a junção de palavras e imagens impressas em uma mesma página; para ser uma história em quadrinhos, tais palavras e imagens devem trabalhar juntas para transmitir uma informação; são exemplares, portanto, de textos verbo-visuais.

A verbo-visualidade pode ser definida como uma forma simbólica complexa de que se reveste o texto, constituída por elementos verbais e visuais 
(cf. FERES, 2013), ou seja, consiste na relação palavra-imagem presentes nos textos. Nos quadrinhos, as palavras são fragmentos de um sintagma mais geral, juntamente com as imagens, e a unidade da mensagem é feita em um nível superior; no caso dos quadrinhos, especificamente, o diálogo não tem a função de uma simples elucidação, mas faz progredir a ação (narrativa), colocando, na sequência das mensagens, os sentidos que a imagem não traz, enquanto as descriçóes verbais são confiadas à imagem (BARTHES, 1990, p. 34). Conforme afirma Lins (2008, p. 40), na conjunção entre o visual e o linguístico, "o código visual supre lacunas que, por acaso, possam ser deixadas pelo código linguístico e vice-versa e, na análise dos diálogos, a explicação dos fenômenos pode se basear em pistas buscadas em ambos os códigos que compóem os textos".

Nessa perspectiva, no gênero em análise, os modos de organização do discurso precisam ser vistos com um olhar diferente, que considera tanto o texto verbal quanto o não verbal em sua análise, já que ambas as formas textuais contribuirão para sua organização global.

\section{Semiolinguística e os modos de organização do discurso}

A Teoria Semiolinguística de Análise do Discurso, criada pelo linguista francês Patrick Charaudeau, apresenta uma perspectiva multifacetada, buscando informaçóes em diferentes campos do conhecimento e servindo como fonte de pesquisa para os mesmos; possui, então, um caráter transdisciplinar.

De acordo com os pressupostos dessa teoria, o discurso é visto como um "jogo comunicativo", e a produção dos atos de linguagem orienta-se por um propósito de "agir sobre o outro". Dessa forma, o ato de linguagem deve ser visto como um encontro dialético entre dois processos: o processo de Produção, criado por um EU dirigido a um TU destinatário; e o processo de Interpretação, criado por um TU' interpretante, que constrói uma imagem do EU' do locutor.

Ao elaborar sua "gramática do sentido e da expressão", em 1992, Charaudeau tinha por objetivo descrever as categorias da língua do ponto de vista do sentido e da maneira como são usadas pelo locutor para construir um ato de comunicação. Cada texto tem algo a dizer e é organizado de acordo com uma determinada estrutura. 
Segundo Charaudeau (2009a, p. 68), os modos de organização do discurso constituem "os princípios de organização da matéria linguística, princípios que dependem da finalidade comunicativa do sujeito falante". Dessa forma, os quatro modos de organização do discurso são o enunciativo, o argumentativo o descritivo, e o narrativo. Cada um desses modos possui uma função de base e um princípio de organização, e a combinação desses diferentes componentes e modalidades permite compreender os diferentes tipos de discurso (científico, jornalístico, pedagógico etc.).

O Modo Enunciativo refere-se aos protagonistas, seres da fala; este modo organiza as categorias da língua, ordenando-as de forma a que deem conta da maneira pela qual o sujeito falante se "apropria" da língua. O Modo Argumentativo consiste em saber expor e provar causalidades dos acontecimentos, numa visada racionalizante para influenciar o interlocutor. O Modo Descritivo consiste em nomear, localizar/situar e qualificar os seres do mundo, com uma maior ou menor subjetividade. Já o Modo Narrativo consiste em construir a sucessão das açóes de uma história no tempo, com a finalidade de fazer um relato. Esses dois últimos serão detalhados a seguir.

\section{A construção do modo descritivo}

Charaudeau (2009a, p. 113) afirma que descrever consiste em ver o mundo com um "olhar parado", trazendo à existência os seres ao nomeá-los, localizá-los, e atribuir-lhes qualidades que os singularizam. Descrever está estreitamente ligado a contar, porém se difere deste; contar consiste em "expor o que é da ordem da experiência e do desenvolvimento das açóes no tempo" (CHARAUDEAU, 2009a, p. 113). A construção do modo descritivo conta com três tipos de componentes: nomear, localizar/situar e qualificar os seres do mundo, com uma maior ou menor subjetividade. Cada um desses componentes, por sua vez, é implementado por um determinado procedimento discursivo.

Nomear é dar existência a um ser, por meio de uma dupla operação: percep̧ãa e classificaçẫo. Como a percepção e a classificação dependem do sujeito que percebe, é "o sujeito que constrói e estrutura a visão de mundo"; por isso, nomear não é um simples processo de "etiquetagem" de uma referência pré-existente, mas sim o resultado de uma operação que consiste em "fazer existir 
seres significantes no mundo, ao classificá-los" (CHARAUDEAU, 2009a, p. 112). A nomeação está ligada ao procedimento discursivo de identificação.

Localizar/situar é determinar o lugar que um ser ocupa no espaço (localização) e no tempo (situação) e, por um efeito de retorno, atribuir características a esse ser, já que, para sua existência, ele depende de sua posição espaço-temporal (CHARAUDEAU, 2009a, p. 113). Essa localização-situação geralmente aponta para um recorte objetivo do mundo; por isso, tem como procedimento discursivo a construçáo objetiva do mundo. Como procedimentos linguisticos, utilizam-se categorias de língua que têm por efeito estabelecer um enquadre espaço-temporal, que pode produzir dois resultados: a identificação de lugares e épocas de um relato com precisão; ou a não identificação, deixando os lugares e o tempo incertos, vagos, porque o relato não se ancora em nenhuma realidade específica, mas coloca em cena destinos e arquétipos que são atemporais (CHARAUDEAU, 2009a, p. 137).

Qualificar é atribuir a um ser, de maneira explícita, uma qualidade que o caracteriza e o especifica, classificando-o, desta vez, em um subgrupo (CHARAUDEAU, 2009a, p. 115). Charaudeau (2009a, p. 115) afirma que "qualificar é tomar partido". Dessa forma, a qualificação, mesmo que pretenda ser objetiva, revela a ótica do enunciador. Segundo Feres (2012, p. 132), “essa operação é sempre circunstanciada em função de uma tomada de posição (não é possível apontar e descrever seres em sua totalidade, mas tão-somente na perspectiva assumida pelo descritor)"; a partir daí, conclui-se que "não há descriçôes ou referências a priori, mas construtos localizados, que instauram objetos de discurso interpretáveis em relação ao contexto e aos saberes partilhados por um grupo social"; sendo assim, na "qualificação", elegem-se "características, qualidades, que retratam o mundo perspectivamente, de acordo com um modo de olhar, através de um filtro ao mesmo tempo biológico/perceptivo e cultural/interpretativo" (FERES, 2012, p. 132).

$\mathrm{O}$ ato de qualificar permite ao sujeito falante manifestar seu imaginário (individual ou coletivo) da construção e da apropriação do mundo, num jogo de conflito entre visóes normativas, impostas pela sociedade, e suas próprias visóes. Assim, a qualificação, um dos procedimentos discursivos do modo descritivo, faz com que um ser "seja alguma coisa", por meio de suas qualidades e de seus comportamentos, suscitando procedimentos discursivos de construção ora objetiva, ora subjetiva do mundo (CHARAUDEAU, 2009a, p. 116-117). 
Os procedimentos de construção objetiva do mundo consistem em construir uma "visão de verdade sobre o mundo", qualificando os seres por meio de traços que possam ser verificados por seu interlocutor; tais procedimentos estão ligados, portanto, ao imaginário social compartilhado; em textos fictícios, tais procedimentos são utilizados para "criar um efeito de realidade". Os procedimentos de construção subjetiva do mundo consistem em permitir ao sujeito falante descrever os seres do mundo e seus comportamentos por meio de sua própria visão, a qual não é necessariamente verificável; portanto, o universo assim construído está ligado ao imaginário pessoal do sujeito (CHARAUDEAU, 2009a, p. 125).

No entanto, vale ressaltar que o descritivo, diferentemente dos outros modos, não se fecha em si em uma lógica interna e não existe um percurso obrigatório para sua construção; o descritivo está geralmente ligado a outros modos de organização e, sem ser totalmente dependente, ele adquire sentido (ou parte de seu sentido) em função dos outros modos (CHARAUDEAU, 2009a, p. 117). Portanto, a importância dos três componentes da construção descritiva (nomear, localizar/situar, qualificar), com seus procedimentos linguísticos e discursivos, está em sua contribuição para a composição da encenação descritiva, criando determinados efeitos de sentido no texto.

\section{A encenação descritiva}

$\mathrm{Na}$ descrição, o sujeito descritor pode intervir de maneira explícita ou não, produzindo um certo número de efeitos, resultado de uma intenção consciente da parte do sujeito descritor (EUe), visando a manipular a leitura do sujeito destinatário (TUd); tais efeitos são apenas possíveis, já que o leitor real (TUi) pode não percebê-los. Entre os efeitos produzidos por meio da encenação descritiva, podem-se citar: o efeito de saber, os efeitos de realidade e de fiç̧ão, o efeito de confidência e o efeito de gênero.

$\mathrm{O}$ efeito de saber pode ser produzido quando o descritor procede a uma série de identificaçóes e de qualificaçóes que, presumivelmente, o leitor não conhecia, fabricando para si uma imagem de "descritor sábio", conhecedor do mundo, que utiliza seus conhecimentos para trazer a prova da veracidade de seu relato ou argumentação (CHARAUDEAU, 2009a, p. 139).

Os efeitos de realidade e de ficção devem ser tratados juntamente, pois a alternância entre esses dois modos é que constrói o "plano de fundo" (visão 
de mundo) em textos narrativos, como os quadrinhos. $\mathrm{O}$ efeito de realidade é obtido por meio da construção objetiva de mundo, que tenta apresentar um mundo realista (não necessariamente real), segundo o que se crê ser verdade, ligado a um imaginário social compartilhado; nos quadrinhos, o efeito de realidade é criado quando são utilizadas próximas ao real ou estereotipadas, para que o leitor reconheça nelas um mundo realista, por meio de seus saberes de crença e de conhecimento. O efeito de fiç̧ão, por sua vez, é produzido por meio da construção subjetiva de mundo, que: deixa transparecer o ponto de vista do descritor (emoçóes, opinióes, afetos), por meio de metáforas, metonímias, comparações, qualificações; ou culmina na construção de um mundo mitificado, ligado ao imaginário simbólico (em contraste com o mundo realista). É na alternância entre essas duas construçóes que uma narrativa, por mais fantasiosa que seja, pode ter alguma ancoragem no real, seja por semelhança seja por oposição, o que possibilita o estabelecimento de relaçóes, fazendo com que o texto tenha sentido para o leitor.

O efeito de confidência procede de uma intervenção explícita ou implícita do descritor, que exprime sua apreciação pessoal, trazendo uma aproximação de seu interlocutor. Pode-se dizer que o efeito de confidência está estreitamente ligado à estratégia de patemização, ou seja, procura captar o leitor pela visada de "fazer sentir".

Por fim, o efeito de gênero resulta do emprego de alguns procedimentos de discurso que se repetem e são característicos de um determinado gênero para tornar-se signo deste (CHARAUDEAU, 2009a, p. 142). Por exemplo, ao começar um relato por "era uma vez", cria-se o efeito de conto maravilhoso ou conto de fadas.

\section{A construção do modo narrativo}

Para que haja narrativa, segundo Charaudeau, é necessário um "contador" investido de uma intencionalidade, ou seja, de querer transmitir uma certa representação da experiência do mundo a um "destinatário", de uma certa maneira, em um determinado contexto. Contar representa "uma busca constante e infinita"; é uma atividade linguageira cujo desenvolvimento implica uma série de "tensôes e contradiçóes" (CHARAUDEAU, 2009a, p. 153-154). 
O Modo Narrativo, então, consiste em construir a sucessão das ações de uma história no tempo, com a finalidade de fazer um relato. Segundo Cagnin (2014, p. 42), a imagem por si só é uma narrativa, ainda que mínima, pois a ação, elemento essencial da narração, aquele instantâneo figurado na imagem, possibilita deduzir e contar o que aconteceu antes e depois daquele momento "congelado". O modo de organização narrativo caracteriza-se ainda por uma dupla articulação: a construção de uma sucessão de açôes segundo uma lógica que vai constituir a trama da história (a organização da lógica narrativa); a realização de uma representação narrativa, isto é, daquilo que faz com que essa história se torne um universo narrado (a organização da encenação narrativa), aspectos que serão discutidos a seguir.

\section{A lógica narrativa}

Conforme explica Charaudeau (2009a, p. 166), a lógica narrativa é composta por uma sucessão de acontecimentos ligados entre si por uma relação de solidariedade (princípio de coerência); a narrativa produzida, por sua vez, só terá sentido se estiver relacionada a um encadeamento de motivos dirigidos a um fim (princípio de intencionalidade); essas açôes ou esses acontecimentos reagrupam-se em sequências ordenadas segundo um princípio de encadeamento; por fim, essa sucessão de acontecimentos coerente e motivada precisa ocorrer em um enquadramento espaço-temporal, segundo um princípio de localização.

Quanto à localização espaço-temporal, nos quadrinhos, a situação é normalmente no presente, dando a sensação de atualidade, como as açóes estivessem acontecendo no ato de leitura. Cagnin (2014, p. 61) explica que, nos quadrinhos (ocidentais), uma sequência passa por três tempos: é presente o que está sendo lido; é passado o da esquerda, que já foi lido, é futuro o da direita, que vai ser lido. A passagem de tempo nos quadrinhos é expressa, geralmente, pela quantidade de quadros utilizados para expressar uma sucessão de açóes.

\section{A encenação narrativa}

"Quem conta (uma história) não é quem escreve (um livro) nem quem $e ́$ (na vida)". Charaudeau (2009a, p. 183) explica dessa forma o dispositivo narrativo. Nesse sentido, não se deve confundir o indivíduo, ser psicológico e 
social, o autor, ser que escreveu, e o narrador, "ser de papel", que conta uma história; da mesma maneira, são diferentes o leitor real, a quem é demandado um mínimo de competência de leitura, e o leitor, "ser de papel", destinatário de uma história contada por um narrador (CHARAUDEAU, 2009a, 183184). Portanto, toda narrativa depende de uma encenação narrativa.

As histórias em quadrinhos, assim como um filme ou uma peça teatral, articulam dois espaços de significação. Há um espaço externo ao texto (extratextual), onde se encontram os dois parceiros da troca linguageira: o individuo/autor (sujeito comunicante - EUc) e o leitor/espectador real (Sujeito interpretante - TUi); nesse caso, a obra se constitui como veículo de interação entre autor e leitor/espectador, e tal interação se dá no universo situacional ou no mundo real. Há também um espaço interno ao texto (intratextual), onde se encontram o narrador e as personagens - sujeitos enunciadores e destinatários - que imitam o mundo real e representam um mundo imaginado, com seus interlocutores comunicantes e interpretantes; nesse caso, a interação ocorre entre as personagens no interior da própria obra e tal interação se dá no universo discursivo, no mundo da ficção. Consequentemente, pode-se depreender uma dupla mise en scène - uma no mundo da representação, do narrador e das personagens, e outra no mundo da produção e da interpretação dos quadrinhos: 


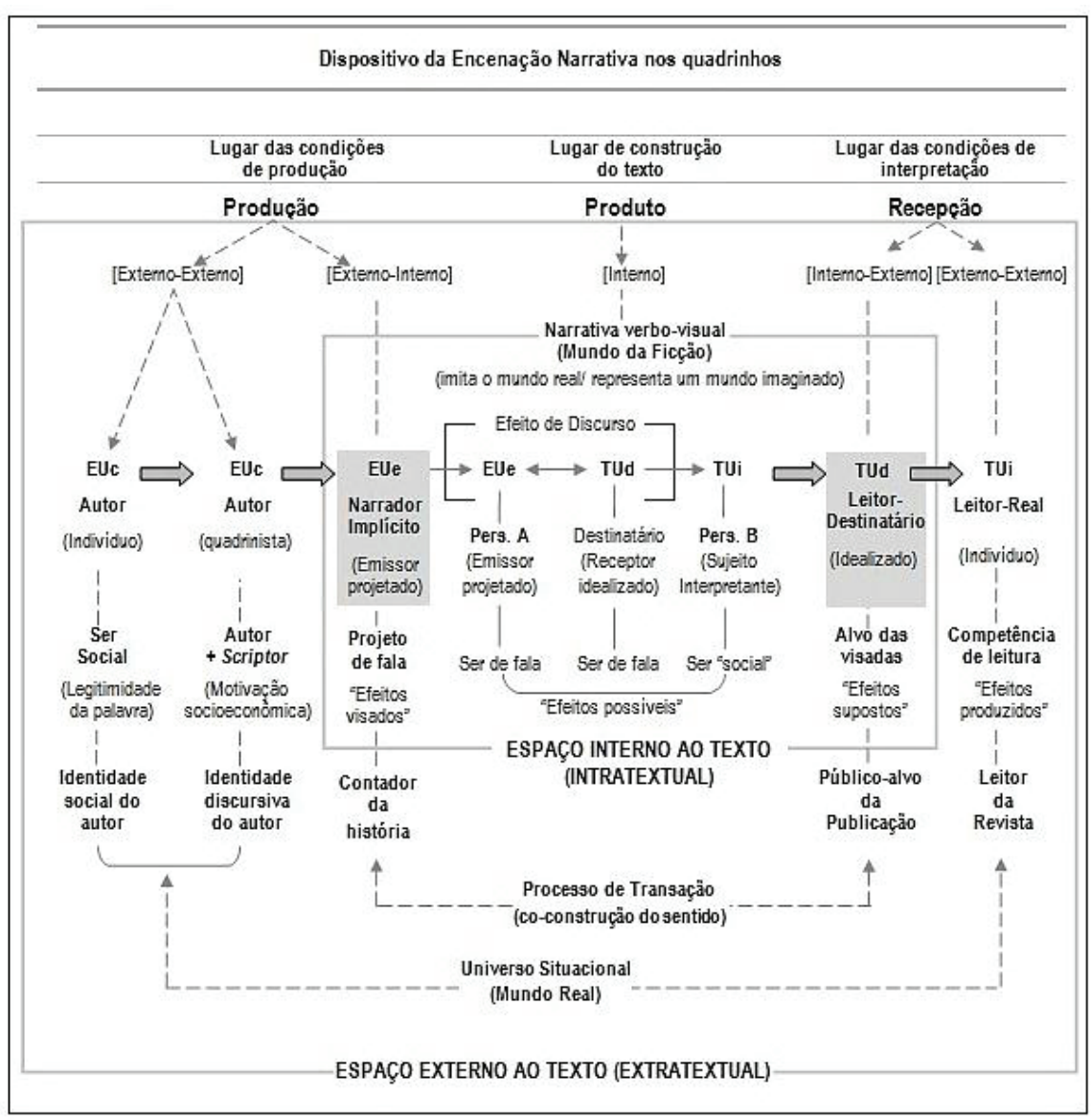

Quadro 1: Dispositivo da Encenação Narrativa nos quadrinhos

Charaudeau (2007, p. 23) afirma que o sentido do ato comunicativo dependerá da relação de intencionalidade instaurada na troca entre as instâncias de produção e de recepção. Como consequência, podem-se observar três lugares de pertinência, conforme representado no Quadro 1: o lugar da instância de produçâo, submetida a certas condiçóes de produção, representado pelos indivíduo/quadrinista (Sujeito comunicante - EUc) e pelo narrador (Sujeito enunciador - EUe); o lugar da instância de recepção, submetida a condiçóes de interpretação, representado pelo leitor da narrativa - Leitor-destinatário (TUd) e Leitor-real (TUi); o lugar do texto como produto, submetido a certas con- 
diçôes de construção, representado pela narrativa verbo-visual. Desse modo, a construção da narrativa não corresponde apenas à intenção do produtor ou do receptor, mas é resultado de uma cointencionalidade que compreende os efeitos visados, os efeitos possiveis e os efeitos produzidos.

$\mathrm{Na}$ encenação narrativa, o narrador produz, discursiva e textualmente, um universo ficcional em que as personagens dialogam (espaço intratextual). Baseando-se em Mello (2004, p. 95), é possível dizer que as personagens são sujeitos de uma enunciação existente no nível discursivo, em um projeto de fala do narrador (EUe). Tais personagens "falam umas às outras, dialogam entre si, em uma situação de comunicação reversível, respeitando as regras conversacionais", utilizando as mesmas estratégias comunicacionais de uma enunciação "real” (MELLO, 2004, p. 96). Assim, as personagens são EUe, TUd e TUi uma para as outras e projetam, ao mesmo tempo, um TUd, que é o leitor ideal idealizado e projetado pelo EUc em sua produção discursiva. E ainda existe um TUi, que é o leitor real da história.

Com relação ao nivel extratextual, nos quadrinhos, há um mesmo sujeito comunicante (EUc), com duas identidades: uma social, e outra discursiva. Em seus trabalhos, Charaudeau difere e relaciona a identidade social e a identidade discursiva. A primeira inclui dados biopsicossociais atribuídos ao sujeito e "tem como particularidade a necessidade de ser reconhecida pelos outros", sendo o que confere ao sujeito seu "direito à palavra", o que funda sua legitimidade (CHARAUDEAU, 2009b). A segunda é construída através de atos de discurso, podendo reconstruir, mascarar, deslocar ou reforçar a primeira. Conforme afirma o teórico, "é neste jogo de vai-vem entre identidade social e identidade discursiva que se realiza a influência discursiva” (CHARAUDEAU, 2009b).

Ao apresentar um quadro comunicacional para o texto dramático, Mello (2004, p. 96) incluiu, no nível situacional, como EUc, além do autor, o que ele denominou scriptor: a figura que materializa o projeto de fala, que o executa, representando, assim, a passagem na relação entre o sujeito-comunicante e o enunciador. No caso da história em quadrinhos, o scriptor poderia ser representado pela equipe de produção (criadores de argumento, roteiristas, desenhistas, arte-finalistas etc.) que materializam o discurso que está no roteiro.

$\mathrm{O}$ espaço de produção externo-externo, ligado ao EUc, também está relacionado com a explicação que Charaudeau $(2007$, p. 23) dá com relação à 
construção de sentido da máquina midiática, pois as revistas de quadrinhos não deixam de ser uma mídia (motivação socioeconômica); nesse sentido, a finalidade do contrato de comunicação midiática se encontra numa tensão entre a visada de fazer saber (ou visada de informação) e a visada de fazer sentir (ou visada de captaçãol patemização), de modo a "prender" os leitores atuais, atrair novos leitores e aumentar o número de vendas das revistas e jornais; além disso, quando as personagens de determinado autor ganham notoriedade, passam a ilustrar publicidade em produtos, campanhas sociais etc.

Ainda na instância de Produção, no espaço externo-interno, o sujeito enunciador (EUe), além da fala das personagens, corresponde à figura do narrador, o "contador da história". Muitos podem pensar que as histórias em quadrinhos não teriam um narrador, já que as personagens "ganham vida" e as cenas se desenrolam durante a leitura; no entanto, essa presença existe, mesmo que às vezes imperceptível. Eisner (2005, p. 10), define narrativa gráfica como "uma descrição genérica de qualquer narração que usa imagens para transmitir ideias", e narrador como "o escritor ou pessoa que controla a narrativa". A presença do narrador (EUe) é melhor percebida quando aparecem textos descritivos, também chamados de legenda - "frases (ou fragmentos de frases) em um quadro, usadas para indicar mudança de tempo ou local em que transcorre a ação, para dar resumo de uma cena anterior, ou veicular comentários oniscientes do narrador”.

No entanto, nos quadrinhos, "a responsabilidade de se contar uma história é compartilhada pelo texto e a imagem” (EISNER, 2005, p. 145). Logo, o narrador está presente na distribuição das personagens, na manipulação da leitura por meio dos jogos de enquadramento (como se fosse a câmera do cinema), na marcação de tempo e ritmo (distribuição de açôes em quadros), ou seja, nas escolhas feitas ao se contar graficamente a história. Além disso, enquanto em gêneros, como o romance e o conto, o narrador é responsável pelas descriçóes verbais, nos quadrinhos, ele é responsável pelas descriçóes visuais (composição das imagens).

$\mathrm{Na}$ instância de recepçâo, há dois sujeitos: o TUd, que representa o destinatário ideal, projetado pelo EUc; o TUi, que representa o leitor real, que pode coincidir ou não com o TUd. Quando TUd e TUi se correspondem, normalmente o projeto comunicativo é bem sucedido e o EUc consegue atingir seu objetivo. 


\section{Verbo-visualidade em a turma do xaxado}

O criador da Turma do Xaxado é o cartunista/quadrinista Antônio Luiz Ramos Cedraz. O autor nasceu em 4 de maio de 1945, na cidade de Miguel Calmon, na Bahia, e faleceu em 11 de setembro de 2014. Seus primeiros contatos com os quadrinhos foram na cidade de Jacobina, onde cresceu e se formou professor. Cedraz teve diversos trabalhos publicados em jornais baianos e ganhou prêmios em concursos e exposições no Brasil e no exterior, entre eles o Prêmio Ângelo Agostini de "Mestre do Quadrinho Nacional". Sua criação mais conhecida foi a Turma do Xaxado, com personagens que retratam a cultura nordestina. Inicialmente, as tiras eram publicadas no jornal A Tarde, de Salvador; posteriormente, as personagens ganharam tiras, livros, jornais e revistas. Por várias vezes, a Turma do Xaxado foi usada pelo Governo da Bahia em campanhas junto ao público infantil, como reciclagem e combate a dengue, e em material paradidático em escolas; em 2003, ganhou apoio da UNESCO (Organização das Nações Unidas para a Educação e a Cultura) ${ }^{1}$. O quadrinista também criou o Estúdio Cedraz para a produção de ilustrações, mascotes e animações para internet, revista e jornais.

De acordo com o site oficial, a Turma do Xaxado é formada por "personagens tipicamente brasileiros, cada um com seu jeito próprio de falar, pensar e agir, passando pelas várias classes econômicas, graus de instrução etc". É uma turma "heterogênea como o povo brasileiro", vivendo histórias que falam dos encantos e problemas do nosso país, mas "sem perder de vista a universalidade da experiência humana". ${ }^{2}$ Em entrevista, Cedraz afirma que sempre foi preocupado com a valorização da cultura brasileira, então achou que era hora de fazer uns personagens "com a sua cara" e que passam "por problemas que também passa grande parte da população brasileira".

Xaxado, personagem principal, é um garoto do interior da Bahia, neto de um famoso cangaceiro que vivia com o bando de Lampiáo. Suas aventuras retratam a vida de pessoas do nordeste, com suas crenças e lendas. Também fazem parte da turma Seu Enoque e Dona Fulô, pais de Xaxado; os amigos Zé

1 Disponível em: http://www.universohq.com/noticias/faleceu-antonio-cedraz-criador-da-turma-xaxado/. Acesso em: 23/10/2015.

2 Disponível em: http://www.xaxado.com.br/turma/turma_xaxado.html. Acesso em: 23/10/2015.

3 Disponível em: http://www.xaxado.com.br/autor/entrevista.html. Acesso em: 23/10/2015. 
Pequeno (o preguiçoso), Marieta (a estudiosa), Arturzinho (filho de um rico fazendeiro); o Padre guloso; os roceiros Tião e Genuíno Gabola; e animais de estimação, como o jumento Veneta, a galinha Odete, o galo Valdisnei, o porco Linguicinha, o cachorro Rompe-Ferro, entre outros.

Para verificar a relação palavra-imagem, serão utilizadas primeiramente duas tirinhas da Turma do Xaxado: uma contém somente o texto, sem imagem (Figura 1), e outra contém somente as imagens, sem texto (Figura 2):
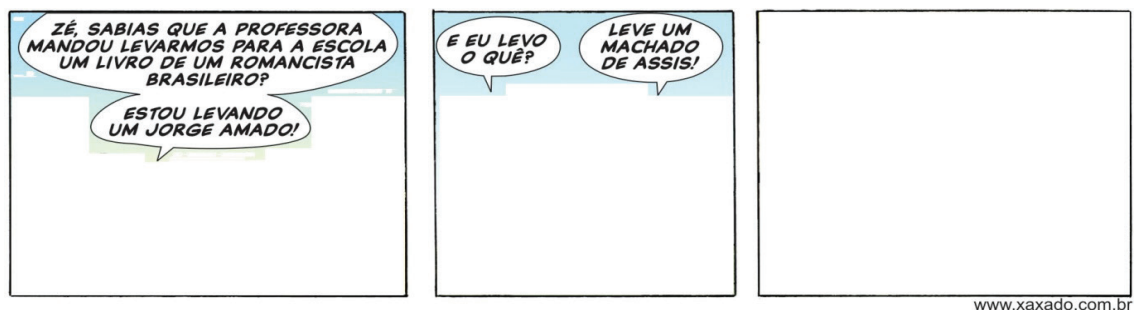

Figura 1 - Tirinha sem imagem
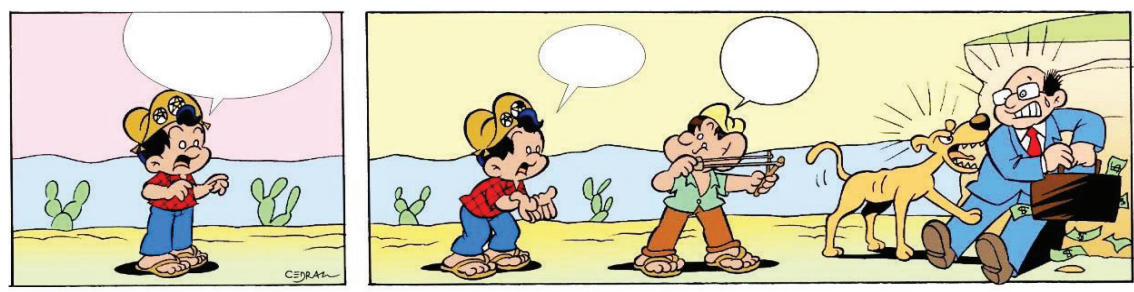

Figura 2 - Tirinha sem texto

Ao apresentar essas tirinhas a participantes de uma oficina intitulada "Leitura de Quadrinhos", apresentada no III Fórum do GP Leitura, Fruição e Ensino (LeiFEn), na Universidade Federal Fluminense (UFF), em 10 de junho de 2015, várias interpretaçóes foram realizadas e novas situações foram criadas, comprovando que o sentido global da tirinha provém da relação texto-imagem e que o conhecimento/reconhecimento do gênero discursivo é importante. Verificou-se que poucos conheciam a Turma do Xaxado, resultado esperado na escolha do material.

$\mathrm{Na}$ tirinha da Figura 1, a maioria desenhou uma pessoa com um machado (ferramenta) na mão. Um participante desenhou alguém com a seguinte fala: "Lá em casa não tem esse de assis não. Só machado normal...". Dois 
participantes desenharam pessoas com livros na mão, querendo dizer que as pessoas levaram livros do autor Machado de Assis. Na tirinha da Figura 2, destacam-se os seguintes textos (na ordem dos três balóes):

1) "Ué, cadê o Zé?" / "Você vai machucar meu cachorro?" / "Não vou. Tô ajudando ele a pegar o bandido!";

2) "O que ocê tá fazendo?" / "Ele é o coletor de impostos" / "Por isso, mandei o Leão atacá!";

3) "Pare" / "Por que você vai fazer isso? / "Eu e Bidu pegamos um político corrupto.";

4) "Meu Deus, o que houve?" / "Não faça isso" / "É o meu dinheiro!";

5) “Ô, Zé! Coitado do cachorro!" / "Vou atirar nele não!" / "Vou atirar é no homi!";

6) “Ô xente! Num faz isso, sô!” / "Vai machucar!” / "Escolhe!”;

7) "Ei, ô!" / "Pra que cê tá fazendo isso?” / "Tô ajudando o moço, ué.”.

Logo depois foram apresentadas as tirinhas originais ao grupo:

XAXADO / Antonio Cedraz

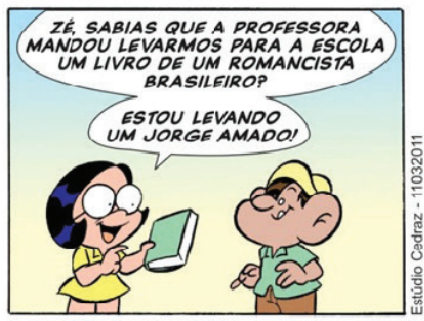

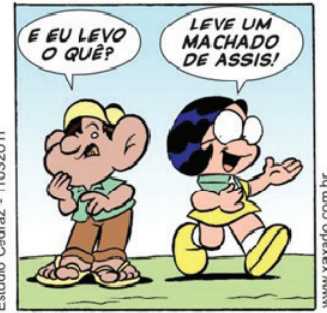

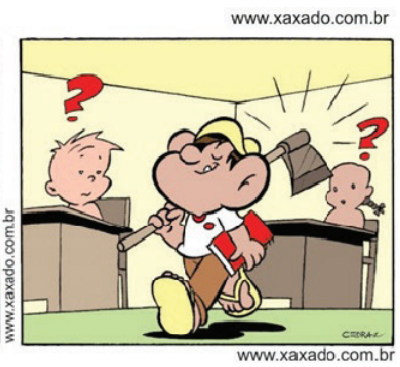

Figura 3 - Tirinha sem imagem completa ${ }^{4}$

XAXADO / Antonio Cedraz
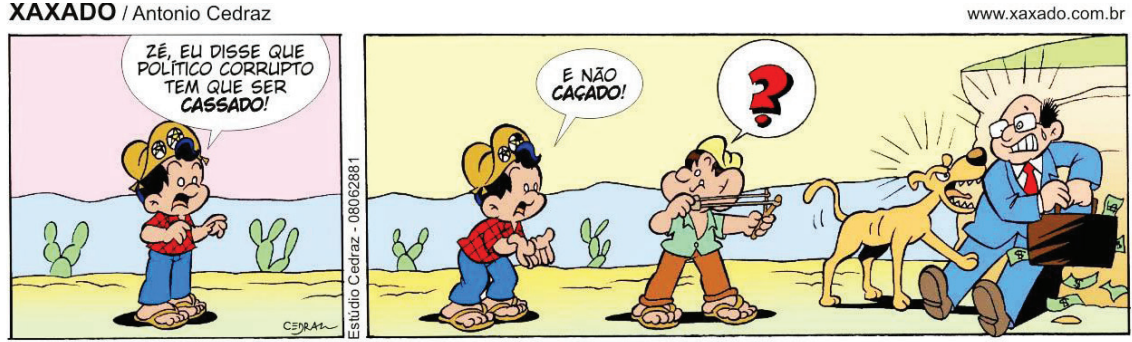

Figura 4 - Tirinha sem texto completa ${ }^{5}$

4 Disponível em: http://www.xaxado.com.br/quadrinhos/tiras.html. Acesso em: 3/6/2015.

5 Disponível em: http://www.xaxado.com.br/quadrinhos/tiras.html. Acesso em: 3/6/2015. 
Com relação à construção descritiva, nas Figuras 3 e 4, é possível observar os componentes: nomeação, qualificação e localização/situação.

Tem-se a nomeação (denominação) no texto verbal de ambas as tirinhas, por meio do vocativo "Zé"; é interessante notar que, na atividade, dois participantes também nomearam a personagem com estilingue, sem conhecê-la, como Zé, apelido de José, comum no nordeste brasileiro, coincidentemente o nome real da personagem (Zé Pequeno); outro fato interessante é que, apesar de não aparecer na tira, o político é identificado em outras tirinhas como "deputado Gatunildo" - o próprio nome o qualifica, pois "gatuno" é sinônimo de ladrão. Além disso, a nomeação está presente nas ilustraçoes, pois a imagem também tem a função de identificação, ao apresentar a personagem: "Marieta perguntou..." (Figura 3), "Xaxado disse..." (Figura 4). O componente nomear está relacionado com o procedimento discursivo de identificação; os seres representam uma referência material (concreta) ou não material (abstrata), e são nomeados por nomes comuns, que os individualizam e classificam, ou por nomes próprios, criando uma identificação específica, nomeando-os em sua unicidade; dessa forma, a identificaçẫo das referências materiais nas imagens: livro, machado, carteira escolar (Figura 3) e estilingue, maleta, dinheiro, cactos (Figura 4) são essenciais para a compreensão do sentido das tiras, apresentando o contexto da história.

A qualificação aparece de forma subjetiva, por meio do uso de esterétipos expressos imageticamente: menina inteligente (óculos, livro na mão); nordestino (chapéu de cangaceiro); político corrupto (terno e maleta de dinheiro na mão). Nesse sentido, a imagem, com seu caráter "codificado", tem grande influência no sentido do texto, pois, conforme afirma Barthes (1990, p. 13), a imagem não é o real, mas é uma reprodução analógica da realidade, que desenvolve, além do próprio conteúdo analógico - cena, objeto, paisagem (mensagem denotada), uma mensagem suplementar, que é o estilo da reprodução (mensagem conotada); tal estilo revela estética ou ideologicamente a visão do autor e remete aos imaginários sociodiscursivos da sociedade que recebe a imagem. O autor ainda acrescenta que o código conotado é provavelmente constituído por uma reserva de estereótipos (esquemas, cores, grafismos, gestos, expressóes, agrupamentos de elementos).

Com relação às imagens estereotipadas, Eisner (2005, p. 21-22) aponta que "a arte dos quadrinhos lida com reproduçóes facilmente reconhecíveis 
da conduta humana. Seus desenhos são o reflexo no espelho, e dependem de experiências armazenadas na memória do leitor para que ele consiga visualizar ou processar rapidamente uma ideia”. Isso torna necessária a simplificação de imagens transformando-as em símbolos que se repetem, estereótipos. "Estereótipo", nesse caso, não apresenta um sentido negativo, ligado a um preconceito; aqui, estereótipo pode ser definido como "uma ideia ou um personagem que é padronizado numa forma convencional, sem individualidade" (EISNER, 2005, p. 21), algo muito comum nos quadrinhos, geralmente carregando valores culturais.

A localização na Figura 3 pode ser identificada da seguinte maneira: a história se passa na escola (localização definida pela imagem das carteiras escolares e livros), na aula de Literatura (situação definida pelo texto). Na Figura 4, a história acontece no sertão nordestino (localização definida pela imagem dos cactos, do chapéu de cangaceiro, do cachorro magro), no momento em que o Zé iria atirar uma pedra no político (situação definida pela imagem). Semiologicamente, a figuração pela imagem desses lugares é perspectivada pelo imaginário sociodiscursivo vigente; tem, portanto, caráter discursivo e apresenta sentidos relevantes para o sentido geral do texto.

A situaçâo, por sua vez, em ambas as figuras, parece ocorrer no presente, como é comum nos quadrinhos, e a referência temporal é não identificada, dando a sensaçấo de atualidade e, como foi dito anteriormente, deixando o tempo incerto, vago, para não se ancorar em nenhuma realidade específica e tornar a cena atemporal.

$\mathrm{Na}$ encenação descritiva, para criar o efeito de realidade e de ficção, as tirinhas tentam mostrar um mundo realista, ligado a um imaginário social compartilhado, quando tenta retratar imagens que nos remetem a uma escola (carteiras com alunos, livros) e ao sertão nordestino (cactos, terra sem vegetação).

Nas respostas dos participantes da oficina, fica claro como o conhecimento/ reconhecimento do gênero discursivo interfere na interpretação (efeito de gênero). As tirinhas em geral têm as seguintes características: seu formato parece "recorte" de jornal; têm caráter sintético e cunho humorístico, às vezes social e/ou político; usam frases curtas, de efeito ambíguo; usam normalmente o presente do indicativo e do imperativo (ideia de o que está sendo enunciado ocorre agora); as personagens e as situaçóes fictícias (diferente da charge); a narrativa tem desfecho inesperado (efeito de humor). 
Todos os textos criados para a Figura 2 (texto sem imagem) estão no presente do indicativo; nos textos 3, 4 e 6 aparece o imperativo. Pode-se verificar também que todas as tirinhas elaboradas tentam criar uma situação de cunho humorístico (social ou político), com desfecho inesperado; o mesmo ocorre nas ilustraçôes criadas para a Figura 1, por meio da criação de imagens que tornassem o texto ambíguo, com exceção dos dois participantes que desenharam pessoas com livros na mão; nesse caso, não se obteve um desfecho interessante e, consequentemente, não se gerou humor. É possível concluir, a partir daí, que essas duas pessoas não levaram em conta as características do gênero tirinha, o que prejudicou sua leitura ao mostrar o texto incompleto.

A lógica narrativa configura-se da seguinte maneira: no princípio de coerência, um quadrinho dá sentido ao outro; o primeiro quadrinho é a abertura, e o último, o fechamento. No princípio de intencionalidade, a sucessão de açóes deve ter uma razão de ser (motivação), dirigidas a um fim; como as tirinhas são histórias curtas, não é fácil identificar o caminho: falta à busca à êxito/fracasso, ainda mais que o final é geralmente inesperado, criando uma quebra de expectativa. No princípio de encadeamento, as açóes ou os acontecimentos reagrupam-se em sequências ordenadas; a sucessão nas tirinhas é normalmente linear e consecutiva, e um quadrinho dá sequência ao anterior. No princípio de localização, tem-se o enquadramento espaço-temporal, já abordado anteriormente, quando foi falado sobre a localização/situação (construção descritiva).

$\mathrm{Na}$ encenação narrativa, o autor é Antônio Cedraz. Como ser social, o fato de ser nordestino lhe confere a legitimidade da palavra; como quadrinista, recebeu vários prêmios e é reconhecido em seu meio. No espaço interno ao texto, nas duas tirinhas, o narrador aparece na disposição/ enquadramento e escolha das imagens; as personagens que constroem a enunciação ficcional, interagindo entre si, são Marieta e Zé Pequeno, na Figura 3; e Xaxado, Zé pequeno, o deputado Gatunildo e Rompe-Ferro (o cão) na Figura 4.

O sujeito destinatário (TUd) das tiras, inicialmente, como eram publicadas no jornal $A$ Tarde, de Salvador (Bahia), eram os adultos da região; posteriormente, passaram a ser direcionadas também ao público infanto-juvenil, principalmente do nordeste brasileiro. Ao ser questionado se seu trabalho estaria mais voltado para o público infantil ou seria direcionado para outras faixas 
etárias, o cartunista respondeu que as tirinhas seriam "meio a meio"; como primeiro foram publicadas em jornais e o público do jornal é mais adulto, o autor tentou fazer uma historinha que agradasse a todos; nas revistas, as histórias são mais amenas, mas "em ambas sempre tem uma coisa de preocupação com a valorização de nossa cultura”, pois sua intenção não era fazer uma historinha apenas divertida, alienada ${ }^{6}$. O sujeito interpretante (TUi), por sua vez, é difícil definir precisamente; com grande público na Bahia, no site oficial da turma, há depoimentos de pessoas de todos os estados brasileiros e a informação de que as tirinhas da Turma do Xaxado, além de serem publicadas em livros, chegaram a ser publicadas em um jornal de Porto Alegre. De qualquer maneira, como retrata nossa cultura, facilmente um brasileiro de qualquer parte do país reconhecerá o significado das tiras, por meio de sua experiência e seu conhecimento de mundo (saberes de crença e de conhecimento).

\section{Considerações finais}

O presente artigo, sob o olhar da Teoria Semiolinguística de Análise do Discurso (CHARAUDEAU, 1992; 2009), procurou identificar as estratégias discursivas utilizadas nas tirinhas de a Turma do Xaxado e os efeitos de sentido produzidos por meio da relação palavra-imagem, focalizando as encenaçóes descritiva e narrativa.

Em textos mistos como os quadrinhos, o leitor precisa levar em consideração ambos os elementos (texto e imagens). Nas narrativas verbais, o narrador é quem conduz o leitor; o leitor, por sua vez, em contato com os textos descritivo e narrativo projetará em sua mente representações mentais daquilo que lê. No entanto, como afirmam Santaella \& Nöth (2012, p. 15), não há imagens como representaçóes visuais (desenhos, pinturas, gravuras etc.) que não tenham surgido de imagens na mente daqueles que as produziram, da mesma forma que não há imagens mentais que "não tenham alguma origem no mundo concreto dos objetos visuais". Tal projeção mental refletirá, portanto, a visão de mundo e as experiências do leitor e, para isso, é importante que haja um direcionamento adequado, de forma que ocorra o processo de identificação do interlocutor.

6 Disponível em: http://www.xaxado.com.br/autor/entrevista.html. Acesso em: 23/10/2015. 
Nas narrativas verbo-visuais, por sua vez, as imagens são fornecidas visualmente pelo narrador, que parte de uma construção objetiva de mundo para construir uma visão subjetiva de mundo; espera-se daí que o leitor compreenda, por meio das representaçóes estáticas, aspectos como tempo decorrido, espaço, movimento, som, emoções e situaçóes implícitas. É no espaço entre os quadros que "a imaginação humana capta duas imagens distintas e transforma em uma única ideia”, dando "vida” e sequência à história (MCCLOUD, 1995, p. 66).

\section{Referências}

BARTHES, Roland. O óbvio e o obtuso: ensaios críticos III. Trad. Lea Novaes. Rio de Janeiro: Nova Fronteira, 1990.

CAGNIN, Antonio Luiz. Os quadrinhos: linguagem e semiótica: um estudo abrangente da arte sequencial. Sáo Paulo: Criativo, 2014.

CHARAUDEAU, Patrick. Grammaire du sens et de l'expression. Paris: Hachette, 1992.

. Discurso das mídias. São Paulo: Contexto, 2007 [1 ${ }^{\text {a }}$ reimpressão].

. Linguagem e discurso: modos de organização. São Paulo: Contexto, 2009a [1 ${ }^{\text {a }}$ reimpressão].

. Identidade social e identidade discursiva, o fundamento da competência comunicacional. In: PIETROLUONGO, Márcia. (org.). O trabalho da tradução. Rio de Janeiro: Contra Capa, 2009b. p. 309-326.

EISNER, Will. Quadrinhos e arte sequencial. 3ed. São Paulo: Martins Fontes, 1989.

. Narrativas gráficas. São Paulo: Devir, 2005.

FERES, Beatriz dos Santos. A qualificação implícita no livro ilustrado "A princesa desejosa”. Signum: Estudos da Linguagem, n. 15/3 (esp.), p. 129147. Londrina, dez. 2012.

. A verbo-visualidade a serviço da patemização em livros ilustrados. Bakhtiniana: revista de estudos do discurso, vol.8, n. 2, p. 87-102. São Paulo, jul-dez de 2013.

KRESS, Gunther. Multimodality: challenges to thinking about language. Tesol Quarterly, [s.1.], v. 34, n.2, p. 337-340, Summer 2000.

LINS, M. P. P. O tópico discursivo em textos de quadrinhos. Vitória: EDUFES, 2008. 
MCCLOUD, Scott. Desvendando os quadrinhos. São Paulo: Makron Books, 1995. MEC. Ministério da Educação e do Desporto. Secretaria de Educação Fundamental. Parâmetros Curriculares Nacionais: Lingua Portuguesa. Brasília, 1997.

MELLO, Renato de. Teatro, gênero e Análise do Discurso. In: MACHADO, I. L; MELLO, R. (org.). Gêneros: reflexóes em Análise do Discurso. Belo Horizonte: NAD/FALE/UFMG, 2004. p. 87-106.

MENDONÇA, Maria R. de Souza. Um gênero quadro a quadro: a história em quadrinhos. In: DIONÍSIO, Â. P.; MACHADO, A. R.; BEZERRA, M. A. Gêneros textuais \& Ensino. Rio de Janeiro: Lucerna, 2002, p. 194-207.

O’NEILL, D. Guia Oficial DC Comics: Roteiros. São Paulo: Opera Graphica, 2005. PATATI, C.; BRAGA, F. Almanaque dos quadrinhos: 100 anos de uma mídia popular. Rio de Janeiro: Ediouro, 2006.

RAMOS, Paulo. A leitura dos quadrinhos. São Paulo: Contexto, 2009.

SANTAELLA, L; NÖTH, Winfried. Imagem: Cognição, Semiótica, Mídia. São Paulo: Iluminuras, 2005.

\title{
READING VERBAL-VISUAL TEXTS: THE CONSTRUCTION OF DESCRIPTIVE AND NARRATIVE PROCEDURES IN COMICS
}

\begin{abstract}
This paper aims to study the reading of comics, checking how the narrative and descriptive procedures are constructed through the verbal-visual interface. The research was based on the Semiolinguistics Theory of Discourse Analysis by Patrick Charaudeau (1992; 2009a). As corpus of analysis, Turma do Xaxado comic strips were used, by Antonio Cedraz.
\end{abstract}

KEYWORDS: comics; verbal visuality; semiolinguistics

Recebido em: 26/10/2015

Aprovado em: 01/03/2016 